\title{
Extraction, and Characterization of Carotenoids from 11 Allelopathic Plant Species as Potential Halal Food Colorants and Active Pharmaceutical Ingredients
}

\author{
Rashidi Othman 1,*, Razanah Ramya ${ }^{1}$, Muhammad Azzubair Azeman ${ }^{1}$, Norazian Mohd. \\ Hassan $^{2}$ and Suhair Kamoona ${ }^{3}$
}

${ }^{1}$ International Institute for Halal Research and Training (INHART), Herbarium Unit, Department of Landscape Architecture, Kulliyyah of Architecture and Environmental Design, International Islamic University Malaysia, 53100 Kuala Lumpur, Malaysia

${ }^{2}$ Department of Pharmaceutical Chemistry, Kulliyyah of Pharmacy, International, Islamic University Malaysia, 25200 Kuantan, Malaysia

${ }^{3}$ Department of Pharmacy, Al-Manara College for Medical Sciences, Maysan, Iraq

\begin{abstract}
Carotenoids are a class of natural product compound that are currently being used as colouring agents and widely used in food industry. Carotenoids are bioactive pigments obtained mainly from plants through dietary intake. They possess good features in terms of dietary supplement, food colourant, and polymer stabiliser. The presence of 4 main carotenoids, which are $\beta$-carotene, zeaxanthin, lutein, and violaxanthin, were determined in 4 classes of allelopathic plant groups namely trees, ferns, grasses and herbaceous plants. This research aims to explore the carotenoid's content and composition in 11 allelopathic species by HPLC analysis. A. auriculiformis (tree) was found to have the highest total carotenoid concentration $(146.36 \mu \mathrm{g} / \mathrm{g} \mathrm{DW})$ that was substantially higher than all other species tested whereas the lowest total carotenoid concentration was found in $S$. palustris (fern) $(3.76 \mu \mathrm{g} / \mathrm{g} \mathrm{DW})$. Lutein and $\beta$ carotene were detected highest in A. auriculiformis (tree), with $1024 \pm 25.5 \mu \mathrm{g} / \mathrm{g} \mathrm{DW}$ and $37.55 \pm 3.16 \mu \mathrm{g} / \mathrm{g} \mathrm{DW}$, respectively. Violaxanthin and zeaxanthin were found substantially highest in $M$. cajuputi (tree) $(5.02 \pm 0.5 \mu \mathrm{g} / \mathrm{g} \mathrm{DW})$ and S. palustris (fern) $(5.88 \pm 0.19 \mu \mathrm{g} / \mathrm{g} \mathrm{DW})$, respectively.
\end{abstract}

Keywords: Allelopathic species, carotenoids, active pharmaceutical ingredients, grass, fern, herb, tree.

\section{INTRODUCTION}

Carotenoids are a class of natural product compounds that are currently being used as colouring agents and widely used in food industry. Carotenoids occur widely in nature and, in general, these coloured compounds are obtained from fruits and vegetables. Currently, the carotenoids used in industrial processes are synthesized chemically, and some carotenoids are extracted from plants, algae, and animals [1,2]. Plants produce biochemical that are of importance in the healthcare, food, flavour and cosmetics industries. Whilst plant cell culture system or technology represents a potential renewable source of valuable medicinal, flavours, essences and colourants that cannot be produced by microbial cells or chemical syntheses. Currently, these and many other natural products are produced solely from massive quantities of whole plant parts [3,4]. Recent advances in molecular biology, enzymology, physiology and fermentation technology of plant cell cultures suggest

*Address correspondence to this author at the International Institute for Halal Research and Training (INHART), Herbarium Unit, Department of Landscape Architecture, Kulliyyah of Architecture and Environmental Design, International Islamic University Malaysia, 53100 Kuala Lumpur, Malaysia; Tel: +6012 6644772; Fax: +603 61964864; E-mail: rashidi@iium.edu.my that these systems will become a viable source of important natural products. Plant pigments are labile: they can be easily altered, and even destroyed. On the basis of their chemical structures, pigments can be classed into four families, i.e. tetrapyrroles (e.g. chlorophyll), carotenoids (e.g. beta-carotene), polyphenolic compounds (e.g. anthocyanins), and alkaloids (e.g. betalains). Colourants in plants arise from two main classes of pigments, carotenoids and anthocyanins. Anthocyanins are responsible for the water soluble vacuoles of pink, red, purple and blue pigments that are present in the coloured plant pigments whereas carotenoids are responsible for the orange and yellow lipid soluble pigments in plastids $[5,6]$. Colorants are often added in foods to enhance their visual aesthetics and to promote sales. Although the allowable amount of synthetic colorants is reduced for consumer healthiness reasons in recent years, many kinds of synthetic food dyes are still widely used all over the world due to their low price, high effectiveness and excellent stability [7,8]. As a consequence of these additional pigment needs, the demand in isolated natural colorants has increased as compared with synthetic dyes. However, this need cannot always be satisfied due to the limitation in the 
supply of raw materials because the production of pigments, using conventional plant cultivation methods, is influenced by climatic conditions, plant cultivars and varieties [9]. Consequently, part of plant pigment research is oriented in finding new sources of pigments. This quest is not only directed in finding natural alternatives for synthetic dyes, but also with the aim to discover new taxa and new procedures for the pigment production, for instance, from the different groups of allelopathic plant species such as, grasses, ferns, herbaceous plants and trees. Highlighting the fact that there is a high demand and consumer preferences for natural compounds, therefore, natural carotenoids are focused in this study. 4 types of plant groups from 11 allelopathic species were chooses, which are grasses, ferns, herbaceous plants and trees. Currently, there is no research that correlates between plant class and their carotenoid content. Therefore, the main subject of this study is determination of carotenoid concentrations based on their class, and comparison between plant classes.

\section{MATERIALS AND METHODS}

\section{Sample Preparation}

All 11 plant species were freeze-dried for 72 hours, after which the samples were grounded into a fine powder and stored at $-20^{\circ} \mathrm{C}$ until further analysis.

\section{Extraction of Carotenoids}

The extraction procedure essentially follows the methods described by Othman [10], with some modifications. $0.1 \mathrm{~g}$ of each powdered sample was rehydrated with distilled water and extracted with a mixture of acetone and methanol (7:3) at room temperature until colourless. The crude extracted was then centrifuged for $5 \mathrm{~min}$ at $10000 \mathrm{~g}$ and stored at $4^{\circ} \mathrm{C}$ in the dark, prior to analysis. To extract carotenoids, an equal volume of hexane and distilled water was added to the combined supernatants. The solution was then allowed to separate and the upper layer containing the carotenoids was collected. The combined upper phase was then dried to completion under a gentle stream of oxygen-free nitrogen

\section{Saponification}

Samples were saponified with a mixture of acetonitrile and water (9:1) and methanolic potassium hydroxide solution $(10 \% \mathrm{w} / \mathrm{v})$. Base carotenoids were then extracted by addition of $2 \mathrm{ml}$ hexane with $0.1 \%$ butylated hydroxytoluene $(\mathrm{BHT})$, followed by the addition of $10 \% \mathrm{NaCl}$ until phase separation was achieved. The extracts were washed with distilled water, dried under a gentle stream of oxygen-free nitrogen and re-suspended in ethyl acetate for spectrophotometry and HPLC analysis, as described in detail by Othman [10].

\section{Determination of Total Carotenoid Content}

Total carotenoid concentration was determined by spectrophotometry, according to the method described by Othman [10]. The dried carotenoid was resuspended in $500 \mu \mathrm{L}$ of ethyl acetate for the determination of total carotenoid content. For spectrophotometric analysis, $50 \mu \mathrm{L}$ of the re-dissolved sample was then diluted with $950 \mu \mathrm{L}$ chloroform. Three different wavelengths $\lambda ; 480 \mathrm{~nm}, 648 \mathrm{~nm}$, and $666 \mathrm{~nm}$ were used in measuring the carotenoid-containing solutions using Varian Cary 50 UV-Vis spectrophotometer. The total carotenoid content in chloroform was obtained by using the Wellburn equation [11] as described below:

$$
\begin{aligned}
& \mathrm{Ca}=10.91 \mathrm{~A} 666-1.2 \mathrm{~A} 648 \\
& \mathrm{Cb}=16.36 \mathrm{~A} 648-4.57 \mathrm{~A} 666
\end{aligned}
$$

$C x+c=(1000 A 480-1.42 \mathrm{Ca}-46.09 \mathrm{Cb}) / 202(\mu \mathrm{g} / \mathrm{ml})(3)$

$\mathrm{Ca}=$ concentration of carotenoid at $666 \mathrm{~nm}, \mathrm{Cb}=$ concentration of carotenoid at $648 \mathrm{~nm}$, and $\mathrm{Cx}+\mathrm{C}=$ total carotenoid concentration at $480 \mathrm{~nm}$.

\section{HPLC Analysis of Carotenoids}

The HPLC analysis of carotenoids were performed on an Agilent model 1200 series that comprises of a quarternary pump with autosampler injector, microdegassers, column compartment equipped with thermostat and a diode array detector. The column used was a ZORBAX Eclipse XDB- $_{18}$ end capped 5 $\mu \mathrm{m}, 4.6 \times 150 \mathrm{~mm}$ reverse phase column (Agilent Technologies, USA). The eluents used were (A) acetonitrile:water $(9: 1 \mathrm{v} / \mathrm{v})$ and $(B)$ ethyl acetate. The column separation was allowed via a series of gradient as follows: $0-40 \%$ solvent $B(0-20 \mathrm{~min}), 40-60 \%$ solvent B (20-25 min), 60-100\% solvent B (25-25.1 min), 100\% solvent $B(25.1-35 \mathrm{~min})$ and $100-0 \%$ solvent $B(35-35.1$ $\mathrm{min}$ ) at a flow rate of $1.0 \mathrm{~mL} \mathrm{~min}$. The column was allowed to re-equilibrate in $100 \% \mathrm{~A}$ for $10 \mathrm{~min}$ prior to the next injection. The temperature of the column was maintained at $20^{\circ} \mathrm{C}$. The volume of each injection was $10 \mu \mathrm{L}$. Detection of individual carotenoids was made at the wavelengths of maximum absorption of the carotenoids in the mobile phase: neoxanthin (438 nm), 
violaxanthin (441 nm), lutein (447 nm), zeaxanthin (452 $\mathrm{nm}), \beta$-carotene $(454 \mathrm{~nm}), \beta$-cryptoxanthin $(450 \mathrm{~nm})$ and $\alpha$-carotene $(456 \mathrm{~nm})$. Compounds were identified by co-chromatography with standards and by elucidation of their spectral characteristics using a photo-diode array detector. Detection for carotenoid peaks was in the range of 350 to $550 \mathrm{~nm}$. Individual carotenoid concentrations were calculated by comparing their relative proportions, as reflected by integrated HPLC peak areas, to total carotenoid content determined by spectrophotometry. The total and individual carotenoid concentration was expressed in terms of milligram per $1.0 \mathrm{~g}$ dry weight of freezedried matter ( $\mu \mathrm{g} / \mathrm{g} \mathrm{DW})$.

\section{RESULTS AND DISCUSSION}

Eleven allelopathic species from different plant groups of grasses (Lepironia articulata, Eleocharis ochrostachys, Dapsilanthus disjunctus), ferns (Stenochlaena palustris, Dicranopteris linearis Achrostichum aureum), herbaceous plant (Hanguana malayana) and trees (Acacia auriculiformis, Azadirachta indica, Melaleuca cajuputi) were selected. These 11 species exhibited highly significant differences in total and individual carotenoid content ( $p$ $<0.0001$ ). A. auriculiformis was found to have the highest total carotenoid concentration $(146.36 \mu \mathrm{g} / \mathrm{g}$ DW) that is substantially higher than all other species tested (Table 1). In contrast, the lowest total carotenoid concentration was found in S. palustris $(3.76 \mu \mathrm{g} / \mathrm{g} \mathrm{DW})$. Carotenoid analysis performed by HPLC system detected at least four major carotenoid peaks: violaxanthin, lutein, zeaxanthin and $\beta$-carotene. As shown in Table 1, lutein and $\beta$-carotene are highest in
A. auriculiformis, with $1024 \pm 25.5 \mu \mathrm{g} / \mathrm{g}$ DW and 37.55 $\pm 3.16 \mu \mathrm{g} / \mathrm{g}$ DW, respectively. Violaxanthin and zeaxanthin are substantially highest in M. cajuputi (5.02 $\pm 0.5 \mu \mathrm{g} / \mathrm{g} \mathrm{DW})$ and $\mathrm{S}$. palustris $(5.88 \pm 0.19 \mu \mathrm{g} / \mathrm{g} \mathrm{DW})$.

All eleven species could be grouped into 3 classes depending on the accumulation of specific carotenoid pigments (Table 1, Figures 1, 2 and 3). D. linearis and $A$. auriculiformis were found to have only two individual carotenoid pigments with a relatively high concentration of lutein. E. ochrostachys and $S$. palustris were detected to have three carotenoid pigments whereas the rest were found with all four types of carotenoids. These results established that carotenoid pigments composition and content vary with species. It was noticed that among all individual carotenoids, lutein is the major carotenoid in all 11 plant allelopathic species. According to [12], lutein and catechin are the major allelochemicals in plants. Hence, this proves that in terms of carotenoids, allelopathy plant species contain high lutein concentration because lutein itself is an allelochemical. Genotype and environment interactions have been reported to account for variation in free amino acids, protein, carotenoids and sugar composition [13-18]. Seasonal differences, growing conditions, locations, genotypes and postharvest storage conditions are among the factors that can be significantly affect the quality and nutritional value of plants [19-22]. The bioavailability of carotenoids is a complex issue and depends on many factors [23]. In this study of environment and genotype interactions, the data revealed that variations in total carotenoid content and the concentration of individual carotenoid pigments is due to strong relationship between genotype and plant group. This assumption is

Table 1: Distributions of Total and Individual Carotenoid Content ( $\mu \mathrm{g} / \mathrm{g} \mathrm{DW})$ in 11 Allelopathic Species

\begin{tabular}{|c|c|c|c|c|c|}
\hline Botanical Name & $\begin{array}{c}\text { Total Carotenoid } \\
(\mu \mathrm{g} / \mathrm{g} \text { DW })\end{array}$ & $\begin{array}{l}\text { Violaxanthin } \\
\text { ( } \mu \mathrm{g} / \mathrm{g} \text { DW) }\end{array}$ & $\begin{array}{c}\text { Lutein } \\
\text { ( } \mu g / g \text { DW) }\end{array}$ & $\begin{array}{c}\text { Zeaxanthin } \\
(\mu \mathrm{g} / \mathrm{g} D W)\end{array}$ & $\begin{array}{c}\beta \text {-Carotene } \\
(\mu \mathrm{g} / \mathrm{g} \text { DW) }\end{array}$ \\
\hline Hanguana malayana & 77.99 & $3.90 \pm 0.01$ & $491.1 \pm 26.6$ & ND & $11.77 \pm 8.05$ \\
\hline Dapsilanthus disjunctus & 14.54 & ND & $17.27 \pm 7.46$ & $1.84 \pm 0.11$ & $1.12 \pm 0.04$ \\
\hline Eleocharis ochrostachys & 25.50 & $3.44 \pm 0.01$ & $136.8 \pm 10.6$ & $3.82 \pm 0.05$ & $4.08 \pm 0.71$ \\
\hline Lepironia articulata & 29.96 & $2.68 \pm 1.09$ & $94.46 \pm 8.05$ & ND & $4.64 \pm 0.53$ \\
\hline Stenochlaena palustris & 3.762 & $1.70 \pm 0.01$ & $39.65 \pm 2.66$ & $5.88 \pm 0.19$ & $0.24 \pm 0.23$ \\
\hline Achrostichum aureum & 15.48 & ND & $53.49 \pm 6.64$ & $2.15 \pm 0.27$ & $1.52 \pm 1.39$ \\
\hline Dicranopteris linearis & 131.3 & ND & $716.8 \pm 4.63$ & ND & $18.58 \pm 2.39$ \\
\hline Rhizophora apiculata & 18.51 & ND & $28.50 \pm 3.35$ & $2.13 \pm 0.19$ & $1.34 \pm 0.14$ \\
\hline Azadirachta indica & 18.33 & ND & $102.6 \pm 75.0$ & $4.94 \pm 0.36$ & $4.01 \pm 1.28$ \\
\hline Melaleuca cajuputi & 31.61 & $5.02 \pm 0.5$ & $189.3 \pm 79.7$ & ND & $7.273 \pm 0.36$ \\
\hline Acacia auriculiformis & 146.36 & ND & $1024 \pm 25.5$ & ND & $37.55 \pm 3.16$ \\
\hline
\end{tabular}




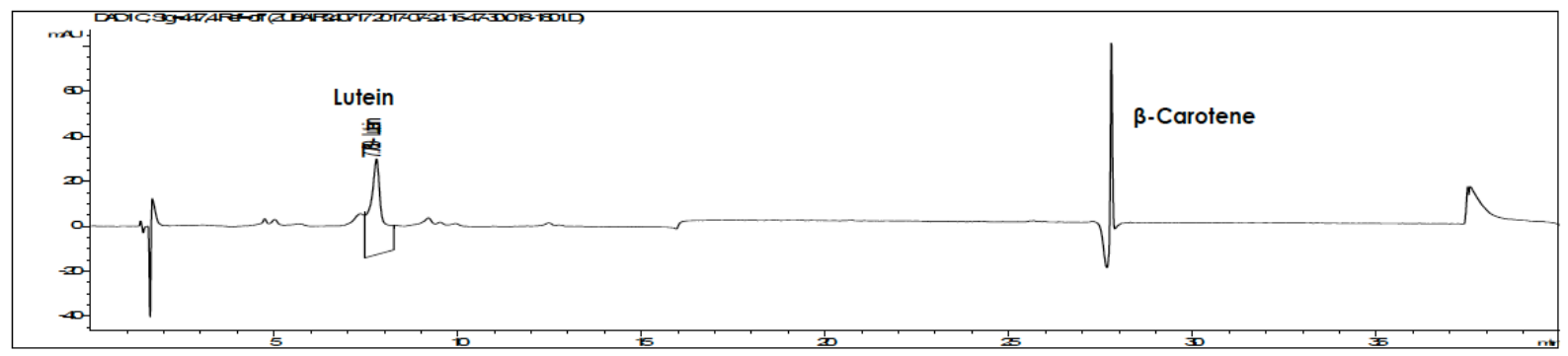

Figure 1: HPLC chromatogram of lutein and $\beta$-carotene in Achrostichum aureum of two carotenoid pigments group.

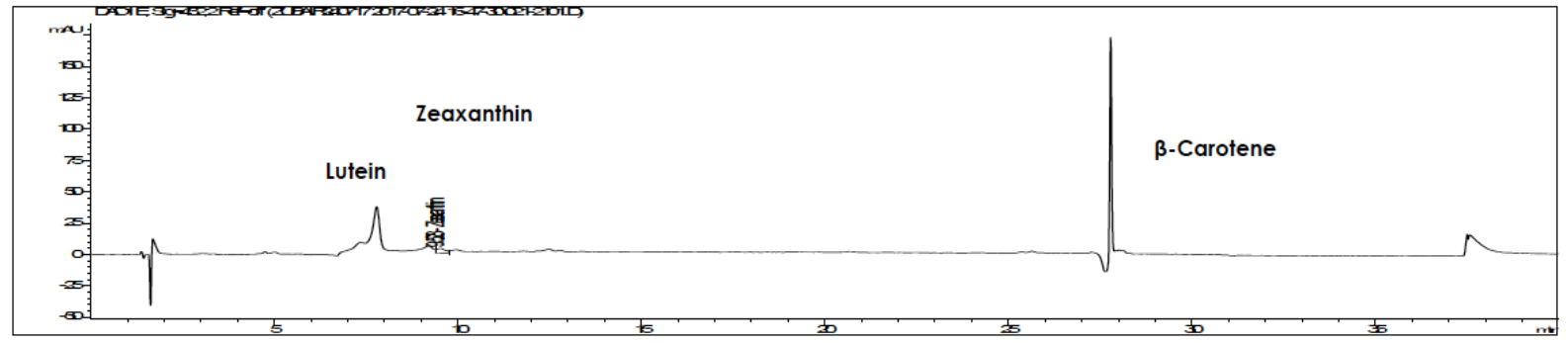

Figure 2: HPLC chromatogram of lutein, zeaxanthin and $\beta$-carotene in Azadirachta indica of three carotenoid pigments group.

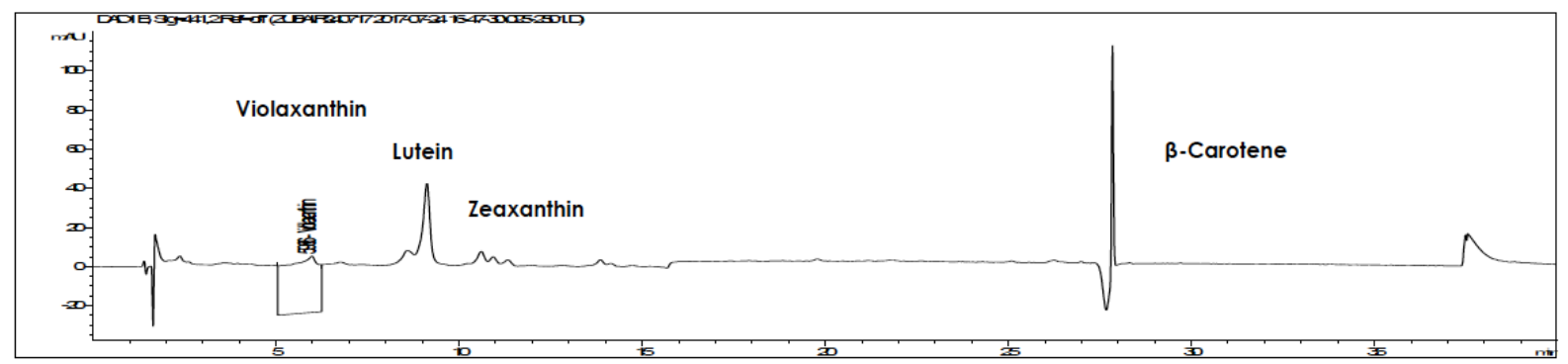

Figure 3: HPLC chromatogram of violaxanthin, lutein, zeaxanthin and $\beta$-carotene in Eleocharis ochrostachys of four carotenoid pigments group.

supported by [24], in their observations of 26 crops over a 43-year period growing seasons; where yield adaptability over time was controlled largely by weather and small variations from year to year in agronomical practices. In other words, major factors influencing yield are location, year and their interactions. A strong relationship and interaction between the intensity of the yellow colour in tuber flesh, total carotenoid content and growing locations has also been reported. [25] demonstrated that environmental factors can exert some influences on the expression of yellow tuber flesh intensity. The correlation between genotypes and environment can be indicative of the particular plant species that are best adapted to certain location. The bioavailability of carotenoids is a complex issue and depends on many factors such as location, year, cultivar and their interactions [26]. In this study on the influences of plant groups and genotype interactions on carotenoid accumulation, the data revealed that variations in both the total carotenoid content and the individual carotenoid compounds exhibit strong relationships between genotype, plant groups and environment (Figures 1-3). Genotype $x$ environment interactions on biochemical composition has been previously reported for phenolics accumulation in plants. There are two possible mechanisms that regulate the differences in carotenoid biosynthesis between allelopathic species:

i. The availability or the abundance of carotenogenic gene transcripts.

ii. The abundance or the presence of structures of sequestering or producing carotenoids.

Therefore, the differences in carotenoid profile from 11 allelopathic species from different growth habits can be explained by the regulation of genes especially zeaxanthin epoxidase (ZEP) and violaxanthin deepoxidase (VDE), presence of structure sequestering carotenoids and environmental stress. As stated by [27], cultivars which have a limited capacity to tolerate excessive light, exhibit an increased 
susceptibility to photooxidative damage. In contrast, cultivars in which carotenoid content is much higher can specifically tolerate excessive light along with many environmental stress conditions by regulating ZEP and VDE. Selecting the appropriate cultivars for the appropriate environmental conditions and appropriate agronomic practices is not only important for yield production, but also for nutritional value and quality of targeted plant.

\section{CONCLUSION}

Carotenoid analysis of 11 allelopathic species detected four major carotenoids of violaxanthin, lutein, zeaxanthin and $\beta$-carotene. A. auriculiformis was found to have the highest total carotenoid $(146.36 \mu \mathrm{g} / \mathrm{g} \mathrm{DW})$ whereas S. palustris had the lowest (3.76 $\mu \mathrm{g} / \mathrm{g} D W) .2$ species $(D$. linearis and $A$. auriculiformis) were found to have only two individual carotenoid pigments with a relatively high concentration of lutein. Other 2 species (E. ochrostachys and S. palustris) were detected to have three carotenoid pigments whereas the rest were found with all four types of carotenoids. This results established that carotenoid pigments composition and content vary with species and there is no relationship between carotenoid content and plant group.

\section{ACKNOWLEDGEMENT}

This work was supported by the Ministry of Higher Education (MOHE) and International Islamic University Malaysia (IIUM) under Research Grant P-RIGS18-0010001.

\section{REFERENCES}

[1] Mezzomo N, Ferreira SRS. Carotenoids functionality, sources, and processing by supercritical technology: A review. J Chem 2016; 1-17. https://doi.org/10.1155/2016/3164312

[2] Othman R, Noh NH, Mohd Hatta FA, Jamaludin MA. Natural Carotenoid Pigments of 6 Chlorophyta Freshwater Green Algae Species. J Pharm Nutr Sci 2018; 8: 1-5. https://doi.org/10.6000/1927-5951.2018.08.01.1

[3] Rodriguez-Amaya DB, Rodriguez EB, Amaya-Farfan J. Advances in food carotenoid research: chemical and technological aspects, implications in human health. Ma1 J Nutr 2006; 12(1): 101-121.

[4] Othman R, Mohd Zaifuddin FA, Mohd Hassan N. Characterisation of Carotenoid and Total Retinol Equivalent Content in Ulam and Medicinal Species as Alternative Food Intervention to Combat Vitamin A Deficiency. J Pharm Nutr Sci 2017; 7: 81-87. https://doi.org/10.6000/1927-5951.2017.07.03.2

[5] Othman R, Mohd Hassan N, Abu Bakar AE, Noh NH, Ahmad Fadzillah N, Mahmad N. Manipulation of Environmental Stress Towards Lutein Production in Chlorella fusca Cell Culture. J Pharm Nutr Sci 2019; 9: 251-257.

[6] Othman R, Md Amin NA, Abu Bakar AE, Ahmad Fadzillah N, Mahmad N. Carotenoid Pigments of Red, Green and Brown
Macroalgae Species as Potential Active Pharmaceutical Ingredients. J Pharm Nutr Sci 2019; 9: 14-19.

[7] Othman R, Mohd Zaifuddin FA, Mohd Hassan N. Isolation and Purification of $\beta$-Carotene from Morinda citrifolia as HPLC Standard and Active Pharmaceutical Ingredient. J Pharm Nutr Sci 2017; 7: 95-99. https://doi.org/10.6000/1927-5951.2017.07.03.4

[8] Santos DT, Albuquerque CLC, Meireles MAA. Antioxidant dye and pigment extraction using a homemade pressurized solvent extraction system. Procedia Food Sci 2011; 1: 15811588.

https://doi.org/10.1016/j.profoo.2011.09.234

[9] Arvayo-Enríquez H, Mondaca-Fernández I, GortáresMoroyoqui P, Lopez-Cervantes J, Rodríguez-Ramírez R. Carotenoids extraction and quantification: a review. Anal Methods 2013; 5(12): 2916-2924. https://doi.org/10.1039/c3ay26295b

[10] Othman R. Biochemistry and genetics of carotenoid composition in potato tubers. Lincoln University; 2009.

[11] Wellburn AR. The Spectral Determination of Chlorophylls a and $b$, as well as Total Carotenoids, Using Various Solvents with Spectrophotometers of Different Resolution. J Plant Physiol 1994; 144(3): 307-313. https://doi.org/10.1016/S0176-1617(11)81192-2

[12] Goiris K, Muylaert K, Fraeye I, Foubert I, De Brabanter J, De Cooman, L. Antioxidant potential of microalgae in relation to their phenolic and carotenoid content. J Appl Phycol 2012; 24(6): 1477-1486. https://doi.org/10.1007/s10811-012-9804-6

[13] Yoo KS, Bang H, Lee EJ, Crosby K, Patil BS. Variation of Carotenoid, Sugar, and Ascorbic Acid Concentrations in Watermelon Genotypes and Genetic Analysis. Hort Environ Biotechnol 2012; 53(6): 552-560.

https://doi.org/10.1007/s13580-012-0014-6

[14] Lester GE, Crosby KM.. Ascorbic acid, folic acid, and potassium content in postharvest green-flesh honeydew muskmelons: Influence of cultivar, fruit size, soil type, and year. J Amer Soc Hort Sci 2002; 127: 843-847.

https://doi.org/10.21273/JASHS.127.5.843

[15] Leskovar DI, Bang H, Crosby KM, Maness N, Franco JA, Perkins-Veazie P. Lycopene, carbohydrates, ascorbic acid and yield components of diploid and triploid watermelon cultivars are affected by deficit irrigation. J Hort Sci Biotechnol 2004; 79: 5-81. https://doi.org/10.1080/14620316.2004.11511739

[16] Perkins-Veazie P, Collins JK, Davis AR, Roberts W. Carotenoid content of 50 watermelon cultivars. J Agr Food Chem 2006; 54: 2593-2597. https://doi.org/10.1021/jf052066p

[17] Stepansky A, Kovalski I, Schaffer AA, Per-Treves R. Variation in sugar levels and invertase activity in mature fruit representing a broad spectrum of Cucumis melo genotypes. Genet Resour Crop Evolut 1999; 46: 53-62. https://doi.org/10.1023/A:1008636732481

[18] Yativ M, Haray I, Wolf S. Sucrose accumulation in watermelon fruits: Genetic variation and biochemical analysis. J Plant Physiol 2010; 167: 589-596. https://doi.org/10.1016/j.jplph.2009.11.009

[19] Dale MFB, Griffiths DW, Todd DT. Effects of Genotype, Environment, and Postharvest Storage on the Total Ascorbate Content of Potato (Solanum tuberosum) Tubers. J Agric Food Chem 2003; 51: 244-248. https://doi.org/10.1021/jf020547s

[20] Hubert J, Galani Y, Mankad PM, Shah AK, Patel NJ, Acharya RR, Talati JG. Effect of Storage Temperature on Vitamin C, Total Phenolics, UPLC Phenolic Acid Profile and Antioxidant Capacity of Eleven Potato (Solanum tuberosum) Varieties. Hortic Plant J 2017; 3(2): 73-89.

https://doi.org/10.1016/j.hpj.2017.07.004 
[21] Griffiths DW, Dale MF, Morris WL, Ramsay G. Effects of season and postharvest storage on the carotenoid content of Solanum phureja potato tubers. J Agric Food Chem 2007; 55(2): $379-85$.

https://doi.org/10.1021/jf0620822

[22] Griffiths DW, Dale MFB. Effect of light exposure on glycoalkaloid content of Solanum phureja tubers. J Agric Food Chem 2001; 49: 5223-5227. https://doi.org/10.1021/jf010656r

[23] Othman R, Mohd Hassan N, Mohd Hatta FA. Influence of Environmental Stress toward Carotenogenesis Regulatory Mechanism through In vitro Model System. In: Carotenoids. INTECH, Croatia, pp. 87-104.
[24] Chloupek O, Hrstkova P. Adaptation of crops to environment. Theor Appl Genet 2005; 111: 1316-1321. https://doi.org/10.1007/s00122-005-0060-x

[25] Lu W, Haynes K, Wiley E. Clevidence B. Carotenoid content and colour in diploid potatoes. J Amer Soc Hort Sci 2001; 126: $722-726$.

https://doi.org/10.21273/JASHS.126.6.722

[26] Fraser PD, Bramley PM. The biosynthesis and nutritional uses of carotenoids. Prog Lipid Res 2004; 43: 228-265. https://doi.org/10.1016/j.plipres.2003.10.002

[27] Havaux M, Niyogi KK. The violaxanthin cycle protects plants from photooxidative damage by more than one mechanism. Proc Natl Acad Sci USA 1999; 96: 8762-8767. https://doi.org/10.1073/pnas.96.15.8762 